\title{
Correction to: Inhibiting reactive oxygen species-dependent autophagy enhanced baicalein-induced apoptosis in oral squamous cell carcinoma
}

\author{
Bo Li ${ }^{1} \cdot$ Mei $\mathrm{Lu}^{1} \cdot$ Xin-Xiang Jiang ${ }^{1} \cdot$ Meng-Xiong Pan $^{1} \cdot$ Jun-Wu Mao ${ }^{1} \cdot$ Mei Chen ${ }^{1}$
}

Published online: 6 October 2020

(c) The Japanese Society of Pharmacognosy 2020

\section{Correction to: J Nat Med (2017) 71:433-441 https://doi.org/10.1007/s11418-017-1076-7}

In the original publication of the article, an incorrect immunofluorescence of GFP-LC3 puncta was included in the Fig. 3a. The correct version of Fig. 3a is provided below.
Publisher's Note Springer Nature remains neutral with regard to jurisdictional claims in published maps and institutional affiliations.
Fig. 3 a Representative images of GFP-LC3 expression patterns in Beclin1 siRNA and control-siRNA cells following baicalein treatment. Cal27 cells transfected with the GFP-LC3 plasmid were used. Scale bar $25 \mu \mathrm{m}$. One-way ANOVA followed by Dunnett's analysis was performed using GraphPad Prism 5. $* * P<0.01$ versus the si-control group, ${ }^{\# \#} P<0.01$ versus the sicontrol + baicalein $(100 \mu \mathrm{M})$ group
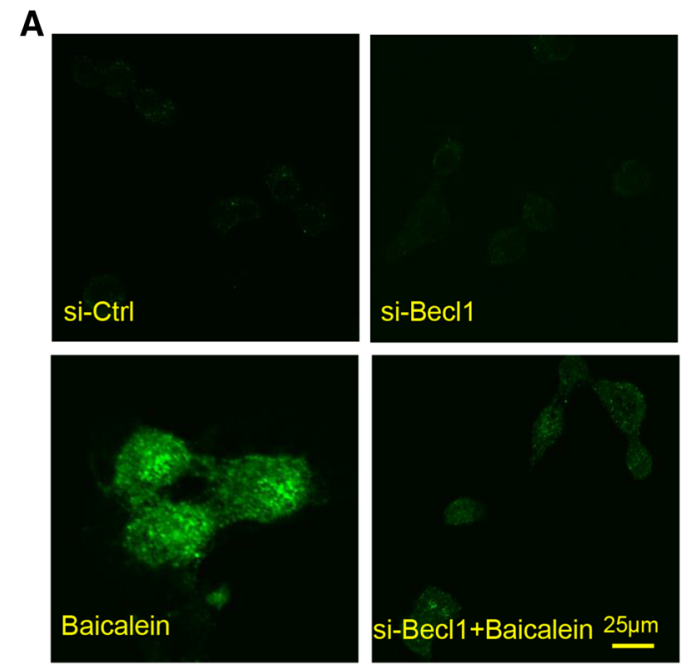

The original article can be found online at https://doi.org/10.1007/ s11418-017-1076-7.

Mei Chen

chm8284@163.com

1 Department of Oral and Maxillofacial Surgery, Affiliated Hospital of Guilin Medical University, Guilin, Guangxi Zhuang Autonomous Region, People's Republic of China 